\title{
Organizational network strengthening effects on antiretroviral therapy initiation and adherence
}

\author{
Chris Bernard Agala, ${ }^{1}$ James C. Thomas, ${ }^{2}$ Bruce J. Fried, ${ }^{3}$ Kristen Hassmiller Lich, ${ }^{3}$ \\ Joseph Morrissey, ${ }^{4}$ Catherine Zimmer, ${ }^{5}$ Kathryn Whetten, ${ }^{6}$ Heidi W. Reynolds ${ }^{1}$
}

${ }^{1}$ MEASURE Evaluation, Carolina Population Center, University of North Carolina, Chapel Hill, NC, USA

${ }^{2}$ MEASURE Evaluation, Carolina Population Center and Department of Epidemiology, Gillings School of Global Public Health, University of North Carolina, Chapel Hill, NC, USA

${ }^{3}$ Department of Health Policy \& Management, Gillings School of Global Public Health, University of North Carolina, Chapel Hill, NC, USA

${ }^{4}$ North Carolina Rural Health Research and Policy Analysis

Center, Sheps Center for Health Services Research, University of North Carolina,Chapel Hill, NC, USA

${ }^{5}$ Odum Institute for Research in Social Science, University of North Carolina, Chapel Hill, NC, USA

${ }^{6}$ Center for Health Policy and Inequalities Research, Duke Global Health Institute, Duke University, Durham, NC, USA

Correspondence to: Chris Bernard Agala, abckris@gmail.com

Cite this as: TBM 2018;8:585-597 doi: 10.1093/tbm/ibx058

\section{Abstract}

The WHO recommends antiretroviral therapy (ART) initiation immediately after HIV diagnosis. When HIV services are fragmented and poorly coordinated, initiation of ART can be delayed. MEASURE Evaluation conducted an organizational network intervention in Addis Ababa, Ethiopia, which increased referral network density and client satisfaction in the intervention versus control networks. The objective of our study was to extend the parent study by assessing effects of network density on the speed of ART initiation and adherence to ART. Measures of client-time since HIV diagnosis, use of ART, satisfaction with HIV-related services, and adherence were obtained from cross-sectional interviews with female service recipients with HIV/AIDS at baseline $(\mathrm{T} 1,402)$ and at 18 -month follow-up $(T 2,524)$ and compared between network sites. We used weighted least squares estimation with probit regression techniques in a structural equation modeling framework for analyses. On average at follow-up, clients in the intervention network were more likely to have quicker ART initiation, and were initiated on ART 15 days faster than clients in the control network. Moreover, quicker ART initiation was associated with higher adherence. A unit increase in speed of ART initiation was associated with 0.5 points increase in latent adherence score in the intervention group $(p<.05)$. Satisfaction with care positively predicted adherence to ART. Network density had no direct effect on ART adherence. This quasi-experiment demonstrated that increased referral network density, through improved HIV client referrals, can enhance speed of ART initiation, resulting in improved adherence.

\section{Keywords}

HIV/AIDS, Antiretroviral therapy initiation, Network theory, Adherence, Africa, Structural equation modeling

\section{INTRODUCTION}

The WHO estimates the adult HIV prevalence rate in Ethiopia at $2.4 \%$, and that of the urban population at $7.7 \%$ [1]. Antiretroviral therapy (ART) is free-of-charge at public providers in Ethiopia through government and donor support, but only $60 \%$ of HIV-positive adults are receiving ART. In one study, only $70 \%$ of those who started ART were still on treatment, highlighting retention challenges including client-loss to follow-up and non-adherence to ART regimens [2]. Lack of access to ART compromises adherence, attenuates the optimum clinical benefit of ART, and is associated with poor

\begin{abstract}
Implications
Practice: The network strengthening intervention assessed in this study was non-complex, rapid, inexpensive, and easily replicable in low-income settings. It utilized local and existing resources within the network to increase access to and speed of ART initiation. Interventionists can adopt this strategy to increase access to and speed of ART initiation in similar settings.
\end{abstract}

Policy: Governments and local organizations in low-resource settings with competing budgetary needs, that often can only facilitate provision of some but not all services HIV/AIDS clients need, should direct their efforts in working together with non-governmental actors and providers to increase the pool of services in catchment areas through client referrals, joint programming, and information and expertise exchange and sharing.

Research: Further research is needed to explore cost-effective, rapid, and feasible interventions that can significantly improve relevant socio-economic, therapy, patient- and condition-related factors to increase adherence to antiretroviral therapy. Future studies should also explore use of behavioral measures of ART adherence. This study provides a framework for the assessment of the effect of organizational network strengthening interventions on speed of ART initiation and adherence.

health outcomes and increased healthcare costs [3]. Adherence is critical to viral suppression and has been shown to positively influence quality of life among HIV/AIDS patients [4-8].

The UNAIDS has set forth the 90-90-90 HIV treatment target in the hopes that all countries will reach the cascade of goals: (i) diagnose $90 \%$ of HIVinfected people; (ii) initiate and retain $90 \%$ of those diagnosed on ART; and (iii) reduce new infections and AIDS-related deaths among those on ART by $90 \%$ from 2010 to 2030 [9, 10]. Initiation and retention in, and adherence to, ART are critical for the 
achievement of the goals of initiating, retaining, and reducing new infections.

HIV/AIDS clients need a variety of services, including ART, treatment for opportunistic infections, counseling, and nutritional services to support their treatment, among others [11]. Despite the recently adopted "Test and Start" policy, which recommends ART initiation immediately after a HIV diagnosis, many clients lack access to services due to uncoordinated, fragmented and siloed care, inconsistent drug supplies, drug rationing, distrust of treatment, and lack of HIV service points $[12,13]$. In addition, fragmented and poorly coordinated health services increase healthcare costs and compromise access and quality of care [14].

Health facilities and home-based care providers, hereinafter referred to as service providers, constitute an organizational referral network when they refer clients for services that they themselves do not provide, as often occurs in low-resource settings, including Addis Ababa, Ethiopia. The strength of the network is dependent upon the level and type of interaction and coordination among service providers. Higher levels of inter-provider interaction, also referred to as high referral network density (actual referral ties as a proportion of total potential ties between providers, measured on a scale of $0-1$ ), has been shown to improve satisfaction with HIV/AIDS care and family planning services by increasing the pool of services in the network [15, 16]. Other studies have also found positive associations between high-density networks and access to mental and other health services [17-23].

Recognizing the potential contribution of organizational networks to health outcomes, the USAID supported a quasi-experimental study conducted by MEASURE Evaluation to test the effect of a referral network strengthening intervention on coordination and integration of HIV care and family planning interventions in two non-contiguous HIV treatment referral networks in Addis Ababa, Ethiopia [15, 16]. The study followed the treatment and referral experiences of 926 HIV-positive women 18-49 years of age who were receiving ART and other healthcare services from provider agencies in the intervention or control sites. Details of the network study have been reported in
Appendix 1 and elsewhere [15, 16]. The intervention was associated with a $55 \%$ increase in network ties (i.e., network density) among 25 service providers (i.e., network nodes), compared with a $60 \%$ decrease in network density among the 26 nodes in the control network $[15,16]$

This study builds upon the MEASURE Evaluation investigation. The objective was to evaluate the effects of the observed increase in network ties in Kirkos on speed of ART initiation and ART adherence.

We hypothesized that (Fig. 1):

1. Increased network density in the intervention network has a direct effect on speed of ART initiation and increases the likelihood of quicker ART initiation among HIV-positive clients;

2. Quicker speed of ART initiation increases observed adherence to ART among clients; and

3. Increased network density in the intervention network has a direct and positive effect on (increases) adherence to ART among HIV-positive clients in that network.

\section{METHODS}

\section{Client interviews}

The MEASURE Evaluation team enrolled clients, using random selection, from one large home-based care service provider that operated in both sites. Women were interviewed in two cross-sections, one (T1) prior to and the other (T2) 18 months following the network intervention. At T1, 402 clients were interviewed: 210 at the intervention site and 192 from the control site; at T2, 524 clients were interviewed: 268 from the intervention site and 256 from the control site. At both times, clients were asked about personal and household-level demographic characteristics, HIV care services needed and received, HIV treatment status, satisfaction with care, and medication adherence. Although some clients may have been interviewed at both $\mathrm{T} 1$ and $\mathrm{T} 2$, participation in $\mathrm{T} 2$ interviews was not conditional on T1. There was no way to know whether a participant in T2 also participated in T1, because at both times clients were randomly sampled from agency caseload lists. Consequently, the samples were essentially independent of each other.

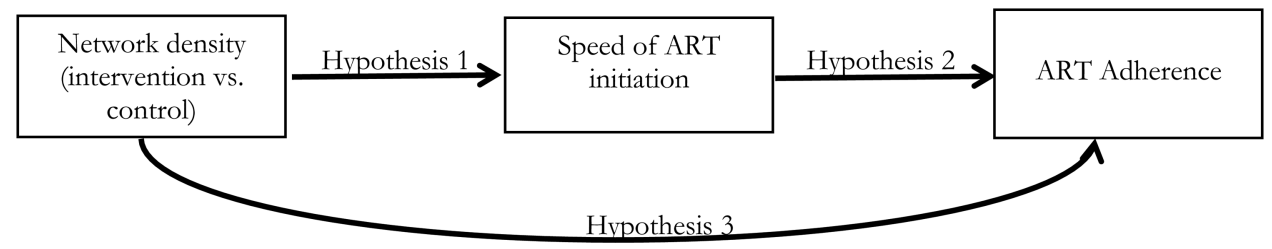

Fig. 1 | Study hypotheses. 


\section{MEASURES}

\section{Speed of ART initiation}

All participants in client interviews were asked how long it had been since they first learned they were HIV-positive, if they were currently on ART, and if so, the length of time they had been on ART. Responses were recorded in weeks, months, and years. For the present study, since we could not tell precisely when a client was truly first infected with HIV, we assumed that the reported date of first HIVpositive test was the date of infection, but we suspect that clients were concurrently diagnosed with HIV and AIDS. The literature suggests that roughly 15-43\% of HIV-positive people in low-income countries present for care with advanced stage (Stage 3 ) disease or CD 4 count at or below 350 cells per cubic millimeter [24, 25]. As of September 2015, the WHO recommends treatment initiation as soon as one tests $\mathrm{HIV}$-positive regardless of $\mathrm{CD} 4$ count, but initiation within 30 days is considered to be on time [25]. Prior to 2016, stage of disease, CD 4 count, and HIV viral load were used in Ethiopia to determine ART initiation [26]. More recently, the Ethiopian Federal Ministry of Health adopted "Test and Start," recommended by PEPFAR guidelines, which requires ART initiation for all clients who test HIV-positive, regardless of stage of disease at diagnosis $[13,26]$.

To generate a measure of speed of ART initiation, we calculated the difference (in days) between the time participants first knew they were HIV-positive and first use of ART. Based on WHO's definition of speed of ART initiation and clinical staging of HIV as described by US government's Federal guidelines, speed of ART initiation was divided into five ordinal categories for analysis: "(1) Less than 31 days," "(2) 31-180 days," "(3) 181-365 days," “(4) 366-3,650 days," and "(5) More than 10 years" [25, 27]. We coded speed of ART initiation such that lower categories indicated quicker initiation.

\section{ART adherence}

Adherence was measured as a continuous latent variable. Clients were asked six questions from a standardized scale, known as the Simplified Medication Adherence Questionnaire (SMAQ) (Appendix 2). In the modeling, the latent variable is estimated using confirmatory factor analysis (CFA). We used multiple-group CFA with structural equation modeling (SEM) to assess measurement invariance for latent adherence, and to develop the measurement model for adherence. SEM is an appropriate analytical methodology for assessing latent outcomes, such as adherence [28]. Measurement invariance is a statistical approach that is used to assess whether respondents interpreted measures conceptually similarly across groups and time and whether participation in an intervention altered the conceptual frame of reference against which a group responded to an indicator over time [29]. The goal of measurement invariance is to ascertain the extent to which a standardized scale measures the same construct across groups and time-points [30]. Results of this analysis showed that adherence was invariant across groups and time; therefore, we concluded that adherence scores could be compared across groups using the same measurement model. To compare levels of latent adherence between intervention and control groups at $\mathrm{T} 1$ and $\mathrm{T} 2$, we used group code analysis, which uses data from both groups in a single SEM model by indicating the groups with a dummy variable [31-33].

\section{Network density}

As reported by Thomas et al. [15, 16], Kirkos had 69 and 101 referral ties and network densities of 0.115 and 0.183 at T1 and T2, respectively. Similarly, Kolfe-Keranyo had 101 and 40 referral ties and network densities of 0.155 and 0.067 at T1 and T2, respectively. We used the same binary variable for comparison of adherence to distinguish the densities of the two networks, where participants were coded as 1 for being in the higher density intervention network or 0 for being in the lower density control network.

\section{Control variables}

Control variables included client age (years), marital status (binary), satisfaction (categorical), education (categorical), and a wealth index (continuous), which was used as a proxy for income (Appendices 3 and 4). We assessed the associations between control variables and outcomes in secondary analyses.

\section{Analysis}

Analyses were performed on four comparison groups-both intervention and control networks at T1 and T2. To test our three hypotheses, we used mean- and variance-adjusted weighted least squares estimation, which is robust and appropriate for modeling ordinal and categorical data, as well as for multiple groups [34, 35]. The coefficients produced depend on the type of the outcome data. In this case, the probit estimates are used to calculate the probability that a woman with particular attributes falls into a specific category of speed of ART initiation [34]. Linear regression estimates are produced for continuous latent ART adherence. First, the invariant SMAQ permitted group comparisons of effects of control variables on latent adherence. Therefore, we ran multiple groups SEM for the whole data set with four study groups (control and intervention groups at T1 and T2-SEM Model 1). Secondly, to compare the levels of adherence and the effect of being in the intervention site on speed of ART initiation and adherence, we ran a comparison SEM for T1 and T2 separately and included being in the intervention as a binary variable (SEM Model 2). All the control variables in SEM Model 
1 were included in SEM Model 2 to check for consistency of results. Finally, we calculated the differences in average speed of ART initiation at T1 and T2 in days to compare differences between networks. Key variables included: network density (intervention/control), time (T1/T2) interaction between networks and time. We used comparative fit index $(\mathrm{CFI})>0.90$, the Tucker Lewis Index (TLI) $>.90$ and root mean square error of approximation (RMSEA) $<0.05$ to assess model fit [36]. We report client statistics for the control variables and outcome variables, model fit indices, effect sizes, $p$-values, and the resulting SEM models. Correlation matrices for the variables are provided in Appendix 5. We used MPlus 7 to conduct data analysis [34].

\section{RESULTS}

\section{Client characteristics}

This study consisted of 926 female clients who were 18-45 years of age and were receiving HIV treatment and treatment support services from 51 service providers in two referral networks. The median age was 34 (range 18-45). Only one-third of the participants lived with their sexual partner, of whom $2 \%$ were not married to them. Nearly one-quarter of all participants had no formal education, and only $15 \%$ had post-primary education. Of the $80 \%$ who reported their weekly income, the average income was 2011 US\$4 (range US\$ 0-72) (Table 1). Based on individual frequencies for the six questions in SMAQ, self-reported adherence ranged from $60 \%$ to $95 \%$ in both networks (Table 2).

\section{Model fit indices}

All estimated models had good fit based on the root mean square error of approximation, Tucker Lewis Index, and comparative fit indices. The multiple groups SEM and comparison SEMs for T1 and T2 had RMSEA <0.6, CFI >0.95, and TLI >0.95 (Table 3).

\section{Speed of ART initiation and adherence}

Our hypotheses tests were conducted using SEM Model 2 (Figs. 1 and 2 and Table 4). For the ordinal speed of ART initiation, the sign of the coefficient indicates the direction of the effect of the variable. A positive coefficient indicates higher likelihood, versus lower for a negative coefficient, of quicker

\begin{tabular}{|c|c|c|c|c|}
\hline Variable & $\begin{array}{l}\text { Kolfe-Keranyo } \\
\text { (control) T1 }\end{array}$ & $\begin{array}{l}\text { Kirkos (interven- } \\
\text { tion) } \mathrm{T} 1\end{array}$ & $\begin{array}{l}\text { Kolfe-Keranyo } \\
\text { (control) T2 }\end{array}$ & $\begin{array}{l}\text { Kirkos (interven- } \\
\text { tion) T2 }\end{array}$ \\
\hline Age $(S D)$ & $32(6)$ & $34(6)$ & $34(5)$ & $34(6)$ \\
\hline \multicolumn{5}{|l|}{ Education, \% } \\
\hline (1) No school & 33 & 16 & 29 & 17 \\
\hline (2) Adult education & 5 & 5 & 7 & 8 \\
\hline (3) Primary (1-4 grades) & 17 & 20 & 22 & 17 \\
\hline (4) Primary (5-8 grades) & 34 & 39 & 29 & 40 \\
\hline (5) Secondary (9-10 grades) & 6 & 13 & 11 & 17 \\
\hline (6) Preparatory (11-12 grades) & 5 & 6 & 1 & 2 \\
\hline (7) Technical/vocational certificate & 0 & 0.5 & 0 & 0 \\
\hline (8) University degree/associate degree & 0.5 & 0.5 & 0 & 0 \\
\hline \multicolumn{5}{|l|}{ Marital status, $\%$} \\
\hline (1) Married & 40 & 26 & 33 & 31 \\
\hline (2) Not Married & 60 & 74 & 67 & 69 \\
\hline Wealth index $(S D)$ & $-1.5(0.9)$ & $-1.1(1.0)$ & $0.6(1.2)$ & $1.4(1.2)$ \\
\hline Income per week in US\$ $(S D)$ & $3(7)$ & $4(7)$ & $5(6)$ & $6(6)$ \\
\hline \multicolumn{5}{|l|}{ Speed of ART initiation, \% } \\
\hline (1) <31 days & 36 & 44 & 30 & 38 \\
\hline (2) 31-180 days & 6 & 4 & 11 & 8 \\
\hline (3) 181-365 days & 19 & 20 & 9 & 16 \\
\hline (4) $366-3,650$ days & 38 & 31 & 43 & 35 \\
\hline (5) $>10$ years & 0.5 & 0.5 & 7 & 3 \\
\hline \multicolumn{5}{|l|}{ Satisfaction with HIV/AIDS care and support, \% } \\
\hline (4) Very satisfied & 59 & 65 & 52 & 49 \\
\hline (3) Somewhat satisfied & 23 & 26 & 42 & 44 \\
\hline (2) Somewhat unsatisfied & 15 & 6 & 4 & 4 \\
\hline (1) Unsatisfied & 3 & 3 & 2 & 3 \\
\hline$N$ & 192 & 210 & 256 & 268 \\
\hline
\end{tabular}

aExchange rate: 2011 US\$ 1 = Ethiopian Birr 17.2836 (Source: National Bank of Ethiopia). 
Table 2 | Patient responses to the six-item adherence questionnaire (SMAQ) at baseline (T1) and follow-up (T2) in the intervention and control networks

\begin{tabular}{|c|c|c|c|c|}
\hline \multirow[b]{2}{*}{ Question } & \multicolumn{2}{|c|}{$\begin{array}{c}\text { T1 Responses to adherence } \\
\text { questions (\%) }\end{array}$} & \multicolumn{2}{|c|}{$\begin{array}{c}\text { T2 Responses to adherence } \\
\text { questions (\%) }\end{array}$} \\
\hline & $\begin{array}{l}\text { Kolfe-Keranyo (control) } \\
\quad n=192\end{array}$ & $\begin{array}{l}\text { Kirkos (intervention) } \\
\quad n=209\end{array}$ & $\begin{array}{l}\text { Kolfe-Keranyo (control) } \\
\qquad n=256\end{array}$ & $\begin{array}{l}\text { Kirkos (intervention) } \\
\quad n=265\end{array}$ \\
\hline $\begin{array}{l}\text { 1. Do you ever forget to } \\
\text { take your medicine? }\end{array}$ & $\begin{array}{l}\text { Yes } 60(31) \\
\text { No } 132(69)\end{array}$ & $\begin{array}{l}\text { Yes } 76(36) \\
\text { No } 133(64)\end{array}$ & $\begin{array}{l}\text { Yes } 66(26) \\
\text { No } 190(74)\end{array}$ & $\begin{array}{l}\text { Yes } 77(29) \\
\text { No } 188(71)\end{array}$ \\
\hline $\begin{array}{l}\text { 2. Are you careless at } \\
\text { times about taking your } \\
\text { medicine? }\end{array}$ & $\begin{array}{l}\text { Yes } 23(12) \\
\text { No } 169(88)\end{array}$ & $\begin{array}{l}\text { Yes } 31(15) \\
\text { No } 178(85)\end{array}$ & $\begin{array}{l}\text { Yes } 21(8) \\
\text { No } 233(92)\end{array}$ & $\begin{array}{l}\text { Yes } 30(11) \\
\text { No } 235(89)\end{array}$ \\
\hline $\begin{array}{l}\text { 3. Sometimes if you feel } \\
\text { worse, do you stop } \\
\text { taking your medicines? }\end{array}$ & $\begin{array}{l}\text { Yes } 14(7) \\
\text { No } 178(93)\end{array}$ & $\begin{array}{l}\text { Yes } 19(9) \\
\text { No } 190(91)\end{array}$ & $\begin{array}{l}\text { Yes } 21(8) \\
\text { No } 233(92)\end{array}$ & $\begin{array}{l}\text { Yes } 24(9) \\
\text { No } 241 \text { (91) }\end{array}$ \\
\hline $\begin{array}{l}\text { 4. Thinking about the last } \\
\text { week. How often have } \\
\text { you not taken your } \\
\text { medicine? }\end{array}$ & $\begin{array}{l}\text { Never } 162(84) 1-2 \\
\text { times } 22(11) 3-5 \\
\text { times } 6(3)>5 \text { times } \\
2(1)\end{array}$ & $\begin{array}{l}\text { Never } 169(81) 1-2 \\
\text { times } 33(16) 3-5 \\
\text { times } 7(3)>5 \text { times } \\
0(0)\end{array}$ & $\begin{array}{l}\text { Never } 222(87) 1-2 \\
\quad \text { times } 27(11) 3-5 \\
\text { times } 5(2)>5 \text { times } \\
2(1)\end{array}$ & $\begin{array}{l}\text { Never } 223(84) 1-2 \\
\text { times } 33(12) 3-5 \\
\text { times } 7(3)>5 \text { times } \\
2(1)\end{array}$ \\
\hline $\begin{array}{l}\text { 5. Did you not take any of } \\
\text { your medicine over the } \\
\text { past weekend? }\end{array}$ & $\begin{array}{l}\text { Yes } 9(5) \\
\text { No } 178(95)\end{array}$ & $\begin{array}{l}\text { Yes } 15(7) \\
\text { No } 194(93)\end{array}$ & $\begin{array}{l}\text { Yes } 13(5) \\
\text { No } 235(95)\end{array}$ & $\begin{array}{l}\text { Yes } 11(5) \\
\text { No } 254(95)\end{array}$ \\
\hline $\begin{array}{l}\text { 6. Over the past } \\
3 \text { months, how many } \\
\text { days have you not } \\
\text { taken any medicine } \\
\text { at all? }\end{array}$ & $\begin{array}{l}\leq 2 \text { days } 183(95) \\
\quad>2 \text { days } 9(5)\end{array}$ & $\begin{array}{l}\leq 2 \text { days } 189(90) \\
\quad>2 \text { days } 20(10)\end{array}$ & $\begin{array}{l}\leq 2 \text { days } 227(89) \\
\quad>2 \text { days } 28(11)\end{array}$ & $\begin{array}{l}\leq 2 \text { days } 244(92) \\
\quad>2 \text { days } 21(8)\end{array}$ \\
\hline
\end{tabular}

Table 3 | Model fit indices for multiple groups SEM (T1 and T2 control and intervention) and control and intervention groups comparison SEM at T1 and T2

\begin{tabular}{|c|c|c|c|}
\hline Model fit indices & $\begin{array}{l}\text { Estimates for SEM Model } 1 \\
\text { (T1 and T2 control and } \\
\text { intervention groups) }\end{array}$ & $\begin{array}{l}\text { Estimates for SEM } \\
\text { Model } 2 \text { at T1 }\end{array}$ & $\begin{array}{c}\text { Estimates for SEM } \\
\text { Model } 2 \text { at T2 }\end{array}$ \\
\hline \multicolumn{4}{|l|}{ Chi-square test of model fit } \\
\hline Value & 188.13 & 56.27 & 63.28 \\
\hline Degrees of Freedom & 144 & 34 & 34 \\
\hline$p$-value & .01 & .01 & .00 \\
\hline \multicolumn{4}{|l|}{$\begin{array}{l}\text { RMSEA (Root Mean Square Error Of } \\
\text { Approximation) }\end{array}$} \\
\hline Estimate & 0.04 & 0.04 & 0.04 \\
\hline 90\% C.I. & $0.02-0.05$ & $0.02-0.06$ & $0.03-0.06$ \\
\hline Probability RMSEA $\leq .05$ & .95 & .79 & .83 \\
\hline $\mathrm{CFI} / \mathrm{TLI}$ & $0.988 / 0.985$ & $0.96 / 0.94$ & $0.989 / 0.984$ \\
\hline $\begin{array}{l}\text { WRMR (Weighted Root Mean Square } \\
\text { Residual) }\end{array}$ & 1.65 & 0.86 & 0.83 \\
\hline
\end{tabular}

speed of ART initiation. For hypothesis 1, increased network density was associated with higher likelihood of quicker speed of ART initiation $(p<.05)$ (Table 4). Comparisons of speed of ART initiation revealed that on average a client in the intervention network was initiated on ART 70 days earlier compared with their counterpart in the control at T2. However, the intervention network had quicker ART initiation even at $\mathrm{T} 1$ than control. Taking the difference at $\mathrm{T} 1$ into account, there was a net average effect of 15 days quicker ART initiation in the intervention network compared with control at
T2 (Table 5). For hypothesis 2, our findings showed that speed of ART initiation predicted ART adherence. A unit increase in speed of ART initiation was associated with an increase of 0.5 units of latent adherence to ART $(p<.05)$. Although we found no evidence of direct association between network density and adherence, our results in hypotheses 1 and 2 suggested a possible indirect association, but the test found no significant evidence for our third hypothesis $(p=.07)$ (Table 4 , Figs. 1 and 2 ).

Our findings from SEM Model 1 showed that satisfaction with care significantly predicted adherence 
Table 4 | Estimates of effects of the intervention on speed of ART initiation and adherence at baseline (T1) and follow-up (T2) in KolfeKeranyo and Kirkos-SEM Model 2

\begin{tabular}{|c|c|c|c|c|}
\hline \multirow[b]{2}{*}{ Outcome variable } & \multicolumn{2}{|c|}{$\begin{array}{l}\text { Kolfe-Keranyo (control) compared with } \\
\text { Kirkos (intervention) at T1 }\end{array}$} & \multicolumn{2}{|c|}{$\begin{array}{l}\text { Kolfe-Keranyo (control) compared with } \\
\text { Kirkos (intervention) at T2 }\end{array}$} \\
\hline & Estimate & $p$-value & Estimate & $p$-value \\
\hline $\begin{array}{l}\text { 1. Effect of intervention on speed of } \\
\text { ART initiation }\end{array}$ & -0.19 & .11 & -0.31 & $.01 *$ \\
\hline $\begin{array}{l}\text { 2. Effect of intervention on ART } \\
\text { adherence }\end{array}$ & -0.41 & .10 & -0.36 & .32 \\
\hline $\begin{array}{l}\text { 3. Effect of speed of ART initiation on } \\
\text { ART adherence }\end{array}$ & -0.10 & .42 & -0.46 & $.02 *$ \\
\hline
\end{tabular}

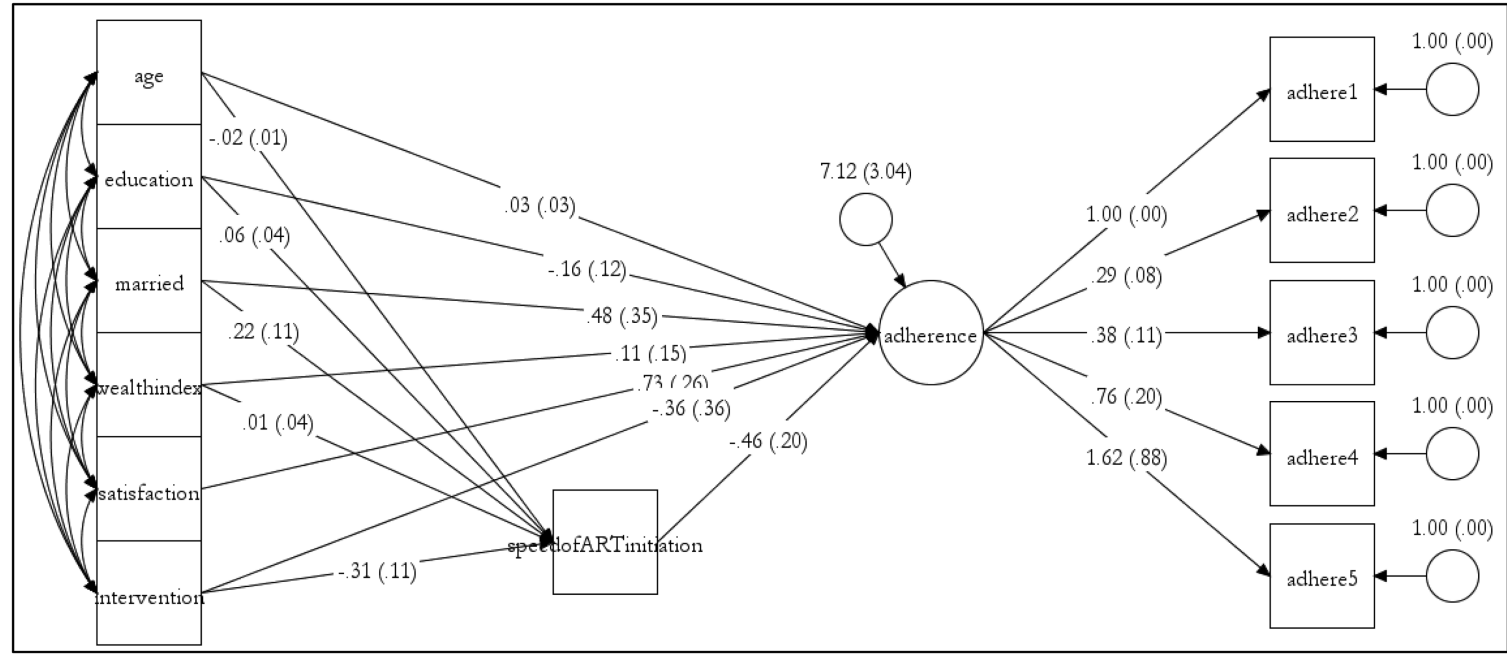

Fig. 2 | SEM model 2 at T2 with estimates of effect sizes and standard errors.

Table 5 | Comparison of unadjusted average number of days of speed of ART initiation between baseline (T1) and follow-up (T2) in KolfeKeranyo and Kirkos

\begin{tabular}{cccc} 
Time point & Kolfe-Keranyo (control) & Kirkos (intervention) & Difference in days \\
T1 & 582 & 527 & 55 \\
\hline T2 & 687 & 617 & 70 \\
Time $\times$ Group (\% difference from T1) & $105(18 \%)$ & $90(17 \%)$ & 15 \\
\hline
\end{tabular}

in intervention network at $\mathrm{T} 1$ and $\mathrm{T} 2$, with a total effect of 0.6 and one-point increases, respectively $(p$ $<.05)$. Married women in the control network at T2 were more likely to be initiated on ART later than their unmarried counterparts in the same network $(p$ $<.05$ ) (Fig. 3 and Table 6). All our findings on associations between dependent variables and control variables for both SEM Model 1 and SEM Model 2 were all consistent.

\section{DISCUSSION}

Our analysis indicates that participants in the intervention network were more likely to be initiated on ART quicker than their counterparts in the control network after the intervention, and in turn, this was associated with greater adherence to ART. Previous findings by
Thomas et al. $[15,16]$ also showed that the intervention was associated with an increase in referral ties, reduction in unmet social service needs, and increased satisfaction. The number of NGOs increased from 5 to 14 and there were four FBOs in Kirkos, compared with a decrease from eight to five NGOs and only one FBO in Kolfe-Keranyo at T2 compared with T1. In addition, 16 providers in Kirkos compared with seven in Kolfe-Keranyo offered home-based care to people living with HIV/AIDS. The increased referral network density (referral ties) that was found in the intervention site, together with increased number of providers there, may have resulted in increased access to and speed of ART initiation.

Although ART speed slowed in both intervention and control sites, we found a 15-day difference in 


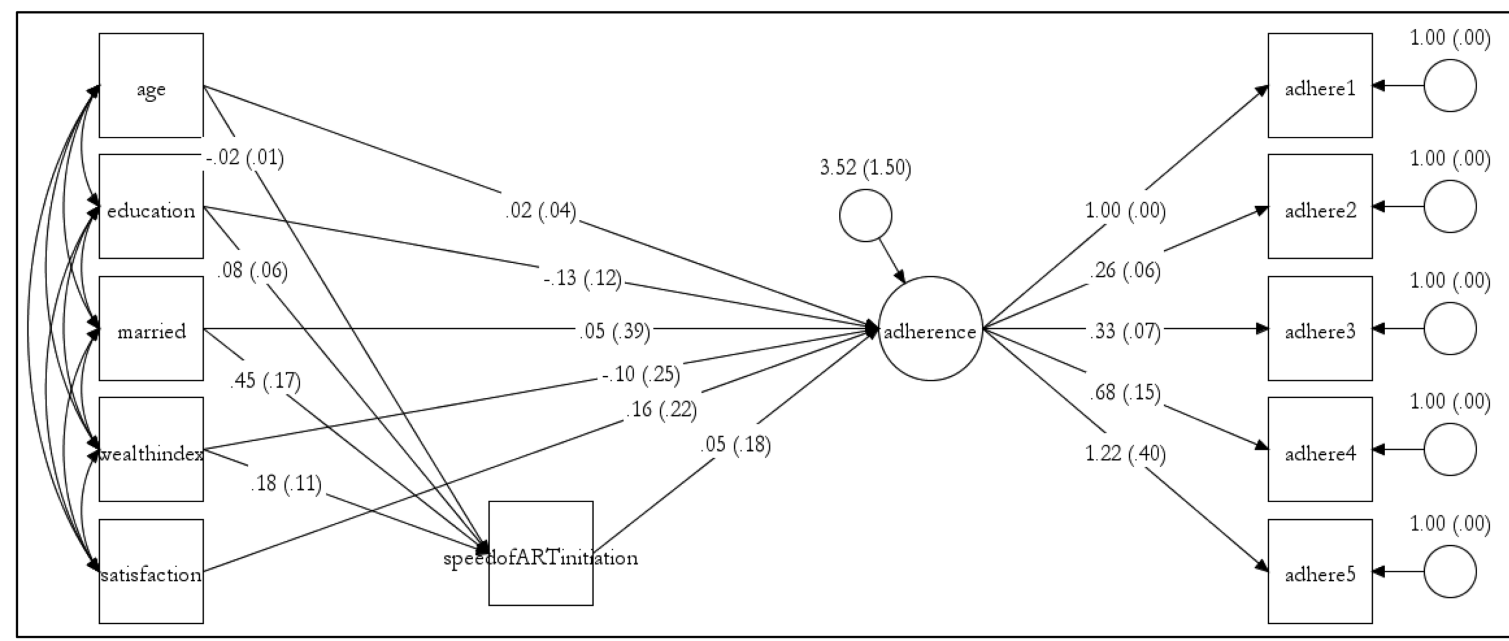

Fig. 3 | SEM model 1 at T1 with estimates of effect sizes and standard errors for the control group. Table 4 contains effect size and standard error estimates of this model for all comparison groups.

Table 6 | Estimates of effects of control variables on speed of ART initiation and ART adherence-SEM Model 1 at baseline (T1) and follow-up (T2) in Kolfe-Keranyo and Kirkos

\begin{tabular}{|c|c|c|c|c|c|c|c|c|}
\hline \multirow{2}{*}{$\begin{array}{l}\text { Speed of ART } \\
\text { initiation on: }\end{array}$} & \multicolumn{2}{|c|}{$\begin{array}{c}\text { Kolfe-Keranyo (control) } \\
\text { at T1 }\end{array}$} & \multicolumn{2}{|c|}{$\begin{array}{c}\text { Kirkos (intervention) } \\
\text { at T1 }\end{array}$} & \multicolumn{2}{|c|}{$\begin{array}{c}\text { Kolfe-Keranyo (control) } \\
\text { at T2 }\end{array}$} & \multicolumn{2}{|c|}{$\begin{array}{c}\text { Kirkos (intervention) } \\
\text { at T2 }\end{array}$} \\
\hline & Estimate & $p$-value & Estimate & $p$-value & Estimate & $p$-value & Estimate & $p$-value \\
\hline Age & -0.02 & .28 & -0.01 & .59 & -0.02 & .10 & -0.02 & .21 \\
\hline Education & 0.08 & .14 & -0.06 & .32 & 0.04 & .51 & 0.09 & .11 \\
\hline Married & 0.45 & $.01 *$ & 0.02 & .91 & 0.45 & $.00 * *$ & 0.01 & .93 \\
\hline Wealth index & 0.18 & .10 & -0.02 & .79 & -0.07 & .27 & 0.10 & .08 \\
\hline \multicolumn{9}{|l|}{ Adherence on: } \\
\hline Age & 0.02 & .62 & 0.01 & .85 & 0.07 & .18 & 0.01 & .89 \\
\hline Education & -0.13 & .27 & -0.18 & .18 & -0.17 & .37 & -0.24 & .23 \\
\hline Married & 0.05 & .89 & 0.72 & .08 & 0.25 & .68 & 0.66 & .23 \\
\hline Wealth index & -0.11 & .67 & -0.28 & .11 & 0.35 & .18 & -0.02 & .94 \\
\hline $\begin{array}{l}\text { Speed of ART } \\
\text { initiation }\end{array}$ & 0.05 & .79 & -0.25 & .19 & -0.33 & .25 & -0.66 & $.03 *$ \\
\hline Satisfaction & 0.16 & .47 & 0.59 & $.02 *$ & 0.65 & .12 & 0.98 & $.01 *$ \\
\hline$N$ & \multicolumn{2}{|c|}{191} & \multicolumn{2}{|c|}{209} & \multicolumn{2}{|c|}{252} & \multicolumn{2}{|c|}{266} \\
\hline $05 ;{ }^{* *} p<0.01$. & & & & & & & & \\
\hline
\end{tabular}

ART initiation favoring the intervention site. This finding could be attributed to sampling or the intervention. It could be that the two networks were not fully comparable at baseline due to client demographic and organizational differences, but our findings show that only the wealth index was higher in Kirkos. However, access to ART is influenced by a variety of factors [37]. Evidence suggests a 15-day quicker ART initiation speed has some clinical benefit for clients with more advanced HIV infection who are likely to develop life-threatening opportunistic infections [25]. In addition, there is some public health benefit for those with higher viral loads and who are sexually active [25]. Cohen et al. [38] reported the benefits of early ART initiation in detail.

According to the WHO's adherence model, adherence requires multi-focal interventions that address health system-related, disease-related, treatment-related factors and client determinants in an integrated manner, and increased and quicker access to ART alone were insufficient to control chronic conditions associated with HIV/AIDS [39]. In this sense, the increased access to ART and other HIV/AIDS services, which were associated with higher network density at the intervention site, may have been insufficient to significantly improve adherence. According to the WHO, the ability of clinics and pharmacies to share information on clients' behavior regarding prescription refills has the potential to improve adherence [39]. Although the intervention did not significantly improve adherence directly, our finding shows that the intervention site, which had higher network density and a higher rate of information exchange, also reported some increased adherence. In addition, study follow-up 
time of 18 months may have been too short for the time required for adherence to measurably improve.

Interestingly, we found that married clients in the control site at T2 were initiated on ART later than unmarried clients in the same network. It is possible that married clients were less likely to seek care earlier due to stigma and discrimination associated with being HIV-positive or fear of divorce or separation from spouses. Abaynew et al. [24] found that people who: lived with their families, had lived more than 2 years with a steady partner, had not disclosed their HIV status and perceived HIV stigma to be high, presented late for HIV treatment. For similar reasons, they may have been less likely to disclose their HIV status to their spouses, even if they had tested and knew they were HIV-positive. This finding may also be due to the control site being more rural compared with the intervention site. People in more rural settings are more likely to live with families than those in more urban ones. Anonymity in more urbanized settings may also be associated with less perceived stigma and promote early testing and treatment seeking behavior.

Our findings also showed that an increase in satisfaction with care was associated with increased adherence. Roberts [40] found client satisfaction with care to be positively associated with HIV treatment adherence and concluded that strengthening relationships between clients and care providers should be a priority. Other studies have also demonstrated that satisfaction is an important factor for uptake, adherence, and retention in treatment and that unsatisfied clients are likely to discontinue seeking care or to change providers [40-42].

Limitations of our study should be noted. One limitation is the potential for social desirability response bias, which may be exacerbated in studies where interview questions are repeated. However, the cross-sectional design of the parent study mitigated this tendency. We also did not observe significant changes in adherence across time in either group. Future studies should explore this association using behavioral measures of adherence to avoid false reporting, which could strengthen the opportunity to establish an association between network density and adherence. Future studies should also explore the association between satisfaction at patient-provider level and network density, and its effect on adherence. There is also a chance that clients misreported time of HIV diagnosis. This could have occurred if clients thought that reporting longer waiting time would be associated with quicker ART initiation, or if they forgot, which would be more likely if standard clinical procedures, including disease stage, CD4 count, and HIV viral load tests, were not followed. Integration of HIV care and full implementation of the "Test and Start" policy are likely to solve this issue.

\section{CONCLUSION}

The UNAIDS FastTrack Initiative is a framework that describes a roadmap for actions required to achieve the 90-90-90 and 95-95-95 treatment cascades by 2020 and 2030 , respectively [9, 10]. It is a scale-up initiative for ART that calls for rapid interventions: to increase value for money and efficient use of limited funds and resources, that are affordable to local governments, and that lead to increased community-based service delivery that brings services closer to the people who need them to improve service uptake $[9,10]$. Our findings suggest that the rapid, affordable, and non-complex referral network strengthening intervention, which was assessed in this study, may be one such initiative. It was associated with an enhanced speed of ART initiation, which significantly and positively predicted adherence. Our findings are significant because Thomas et al. $[15,16]$ also found that the intervention network experienced increased network ties and a decline in unmet client service needs. Adherence to ART is required for viral suppression. According to the UNAIDS, achievement of the third target requires sustained use of HIV treatment and ongoing virological monitoring to verify treatment success and to intervene to support adherence and re-engage those who drop out of treatment [9]. This intervention has promise in contributing to the FastTrack Initiative because it is easily replicable in low-resource settings, such as the sub-Saharan Africa where the burden of HIV/AIDS is highest.

Acknowledgements: The authors would like to express their gratitude to MEASURE Evaluation at the Carolina Population Center at the University of North Carolina at Chapel Hill for granting permission and access to the data that were used in this study. The findings reported in this study have not been previously published. This manuscript is not being simultaneously reported elsewhere. The study that produced the data was funded by the United States Agency for International Development (USAID) through the MEASURE Evaluation project and cooperative agreement GHA-A-00-0800003-00. The views expressed in this publication do not necessarily reflect the views of USAID or the US government. The authors received no funding to produce this manuscript as it is part of the first author's dissertation research.

\section{Compliance with Ethical Standards}

Conflict of Interest: The authors declare no conflict of interest.

Primary Data: The data reported in this manuscript are part of a larger data set from which two manuscripts have been published $[15,16]$. The authors have full control of all the primary data and they agree to allow the journal to review their data if requested. The primary data which were used to produce this manuscript were from a study funded by the United States Agency for International Development (USAID) through the MEASURE Evaluation project and cooperative agreement GHA-A-00-08-00003-00. MEASURE Evaluation is a project supported by the Carolina Population Center, a research center based at the University of North Carolina at Chapel Hill.

Ethical Approval: The design, conduct and result reporting of this study adhered to the ethical compliance requirements of the ethics committees at UNC Chapel, FHI360 and the Ethiopian government and all research work (interviews) were performed only after voluntary consent from the participants. Only human subjects participated in this study. The study was approved by three ethics boards: the University of North Carolina - Chapel Hill, NC, USA, FHI 360 and the Addis Ababa Health Bureau, the Ethiopian government ethics agency. 
Informed Consent: Informed consent was obtained from all individual participants included in the study. All procedures performed in this study were in accordance with the ethical standards of the institutional and/or national research committee and with the 1964 Helsinki declaration and its later amendments.

Appendix 1: Details of the methodology of parent study by MEASURE Evaluation researchers

Data are from a quasi-experimental referral network study conducted by MEASURE Evaluation. Kirkos was the site of an intervention aimed at improving ties among providers. Providers were identified using snowball sampling, beginning with well-known service providers as the seeds. All service providers that offered, and could refer clients to one another for, HIV care and treatment support and family planning services to HIV-positive women of ages 18-49 were included. Saturation was reached when nominated organizational representatives, who were also the interviewees for the study, named service providers that had already been named by others. Ultimately, 25 providers in Kirkos and 26 in Kolfe-Keranyo were included in the study. The data included provider characteristics and linkages among providers. To obtain referral network data, T1 (baseline) and T2 (follow-up) interviews were conducted with nominated key informants in each provider organization about HIV services and the nature and types of referrals offered, provider characteristics, collaborations, joint programs, and linkages with other providers.

\section{Intervention}

A referral network strengthening intervention was implemented in Kirkos where 21 of the 25 providers were represented in at least one of the meetings. Kirkos was selected for the intervention after T1 results showed lower network density there compared with Kolfe-Keranyo. The intervention consisted of a series of three 2-day educational meetings held 2 months apart at different times after T1 data collection. During the meetings, participants learned about strategies for client referral, collaboration, joint programming, and partnerships. They also learned about services offered by other facilities in the network. Service directories, listing contact information and services offered, were developed and shared, with each participating provider receiving at least one directory. No intervention was implemented in Kolfe-Keranyo, the control network.

\section{Characteristics of service providers}

Service providers in the two networks were owned and operated by the Ethiopian government or various types of non-governmental bodies. The government owned and operated 10 out of the 51 service providers, whereas non-governmental organizations (NGOs), faith-based providers (FBOs) or private individuals owned and operated the remainder. Kirkos had significantly fewer (three) government owned and operated providers compared with Kolfe-Keranyo, which had seven. There was a significant increase in the number of providers self-identifying as NGOs in Kirkos from five at T1 to 14 at T2. Conversely, Kolfe-Keranyo experienced a reduction in the number of NGOs from eight at $\mathrm{T} 1$ to five at T2. Providers in both networks reported significant increases in their budgets at T2 compared with T1, Kirkos had a total budget of US\$685,535 and US\$ 1,910,340, whereas Kolfe-Keranyo had US\$583,171 and US\$ 5,510,505 at T1 and T2, respectively. Kolfe-Keranyo had more staff at both time-points compared with Kirkos.

\section{Appendix 2: Measurement of ART adherence}

Patients were asked six questions from a standardized scale, known as the Simplified Medication Adherence Questionnaire (SMAQ):

1. Do you ever forget to take your medicine?

2. Are you careless at times about taking your medicine?

3. Sometimes if you feel worse, do you stop taking your medicines?

4. Thinking about the last week, how often have you not taken your medicine?

5. Did you not take any of your medicine over the past weekend?

6. Over the past three months, how many days have you not taken any medicine at all?

A "yes" response to questions 1, 2, 3, and 5 constituted non-adherence, whereas values $>0$ for question 4 and values $>2$ for question 6 constituted non-adherence. For analysis, the values were flipped such that "no," 0 days and $\leq 2$ days constituted adherence for questions 1, 2, 3 and 5, 4, and 6 , respectively.

Initial assessment of correlations between the six indicators of adherence demonstrated that the question "did you not take any of your medicine over the last weekend" was weakly and negatively correlated $(-0.09)$, with "if at times you feel worse, do you stop taking your medicine" in the T1 intervention group, and was, therefore, excluded from the rest of the analysis.

\section{Appendix 3: Satisfaction with HIV/AIDS Care}

Patient satisfaction with HIV care is an important indicator for QOL and health outcomes among HIV-positive people. The literature suggests that patients who are satisfied with their HIV care are more likely to be retained in care and retention in care is one of the goals of the UNAIDS Fast-Track 90-90-90 Initiative. We hypothesized that adherence and satisfaction with HIV care 
have a concomitant association. Thus, patients with higher adherence scores were more likely to have better health outcomes, including less disease severity, which is likely to lead to higher satisfaction. We also hypothesized that speed of ART initiation indirectly affects satisfaction, through adherence. Thus, patients with higher adherence scores were more likely to be more satisfied with HIV care. Moreover, patients with higher satisfaction scores are more likely to follow providers' instructions and, therefore, report higher satisfaction. However, we did not test the foregoing association due to lack of an appropriate instrumental variable. More adherent patients are more likely to have improved functional status, which may improve their satisfaction.

Patients responded to four questions about satisfaction:

1. Do you feel that your health needs are being met? Would you say that: 1 . All your health needs are being met; 2. Most are being met; 3. Some are being met, or 4. Very few or none are being met?

2. Overall, how satisfied have you been with the care services you receive for your HIV disease? Would you say:

1. Very satisfied; 2. Somewhat satisfied; 3. Somewhat unsatisfied; or 4. Unsatisfied?

3. Overall, how satisfied have you been with family planning services you receive? Would you say: 1 . Very satisfied; 2. Somewhat satisfied; 3. Somewhat unsatisfied; or 4. Unsatisfied?

4. Which HIV or FP services are you particularly very satisfied/unsatisfied with? Responses for this question were free-entry and open-ended format.

We recoded the values from 1-4 to 4-1 to make the scale intuitive such that the highest satisfaction level was coded with the highest number in the scale. These questions were asked of all participants and may have been influenced by satisfaction levels of various types of health services needed and received, for example, family planning services, not just HIV/AIDS care and support services. We could not disentangle the components of the responses for the three questions, which were non-specific to HIV/ AIDS care and support. Therefore, we only used the second question on the list above to measure satisfaction.

\section{Appendix 4: Use of principal components analysis to} generate household wealth index (as described by Filmer D and Pritchett LH. 2001)

Due to the limitations of the data on household income, we used principal components analysis to derive a linear wealth index from 12 observable household asset indicators. Principal components analysis (PCA) is a data reduction process that condenses many observed variables into a single measure. In PCA, components are uncorrelated linear combinations of factors (observed variables) that maximize the total variance. Other researchers have used this methodology to estimate linear wealth indices when income or expenditure data were not available for inclusion in statistical analyses. Compared with income, this index better reflected a household's long-term economic status and overall economic well-being. To generate the wealth index, we included the following household assets, all were measured as categorical and each category was converted to binary format:

1. Material used to make the floor, walls and roof of the main house,

2. Main type of toilet,

3. Main source of drinking water,

4. Main source of energy for cooking, and

5. Whether the household owned a car, bicycle, refrigerator, television set, mobile phone, or a radio.

The histogram of the first principal component, while not normally distributed, depicts a better distribution when compared with that of income.

\section{Appendix 5: Correlation matrices}

1. Correlation matrix for T1 control group-for SEM Model 1

\begin{tabular}{|c|c|c|c|c|c|c|c|c|c|c|c|}
\hline & Age & Education & Married & $\begin{array}{l}\text { Wealth } \\
\text { index }\end{array}$ & Adhere1 & Adhere2 & Adhere3 & Adhere4 & Adhere5 & $\begin{array}{c}\text { Speed } \\
\text { of ART } \\
\text { initiation }\end{array}$ & Satisfaction \\
\hline Age & 1.00 & & & & & & & & & & \\
\hline Education & 0.02 & 1.00 & & & & & & & & & \\
\hline Married & 0.13 & 0.10 & 1.00 & & & & & & & & \\
\hline Wealth index & 0.12 & 0.31 & 0.08 & 1.00 & & & & & & & \\
\hline Adhere1 & 0.05 & -0.04 & 0.02 & -0.05 & 1.00 & & & & & & \\
\hline Adhere2 & -0.11 & -0.25 & -0.21 & -0.05 & 0.22 & 1.00 & & & & & \\
\hline Adhere 3 & -0.12 & -0.38 & -0.12 & -0.13 & 0.43 & 0.63 & 1.00 & & & & \\
\hline Adhere4 & 0.14 & -0.04 & 0.10 & -0.18 & 0.73 & 0.06 & 0.35 & 1.00 & & & \\
\hline Adhere 5 & 0.06 & -0.11 & 0.01 & 0.06 & 0.75 & 0.32 & 0.51 & 0.70 & 1.00 & & \\
\hline $\begin{array}{l}\text { Speed of ART } \\
\text { initiation }\end{array}$ & -0.04 & 0.18 & 0.21 & 0.20 & 0.02 & -0.09 & 0.05 & -0.06 & -0.02 & 1.00 & \\
\hline Satisfaction & -0.04 & -0.07 & -0.03 & -0.16 & -0.07 & 0.18 & 0.23 & 0.12 & 0.07 & -0.07 & 1.00 \\
\hline
\end{tabular}


2. Correlation matrix for T1 intervention group-for SEM Model 1

\begin{tabular}{|c|c|c|c|c|c|c|c|c|c|c|c|}
\hline & Age & Education & Married & $\begin{array}{l}\text { Wealth } \\
\text { index }\end{array}$ & Adhere1 & Adhere2 & Adhere3 & Adhere4 & Adhere5 & $\begin{array}{c}\text { Speed } \\
\text { of ART } \\
\text { initiation }\end{array}$ & Satisfaction \\
\hline Age & 1.00 & & & & & & & & & & \\
\hline Education & -0.03 & 1.00 & & & & & & & & & \\
\hline Married & 0.10 & 0.07 & 1.00 & & & & & & & & \\
\hline Wealth index & 0.00 & 0.26 & -0.03 & 1.00 & & & & & & & \\
\hline Adhere1 & -0.08 & -0.15 & 0.09 & -0.15 & 1.00 & & & & & & \\
\hline Adhere2 & 0.09 & -0.07 & -0.01 & -0.23 & 0.30 & 1.00 & & & & & \\
\hline Adhere3 & -0.09 & 0.11 & 0.00 & 0.11 & 0.44 & 0.24 & 1.00 & & & & \\
\hline Adhere4 & 0.02 & -0.19 & 0.17 & -0.16 & 0.80 & 0.21 & 0.31 & 1.00 & & & \\
\hline Adhere5 & 0.15 & -0.08 & 0.18 & -0.06 & 0.71 & 0.55 & 0.51 & 0.73 & 1.00 & & \\
\hline $\begin{array}{l}\text { Speed of ART } \\
\text { initiation }\end{array}$ & -0.04 & -0.09 & 0.00 & -0.06 & -0.18 & -0.27 & -0.21 & 0.15 & -0.04 & 1.00 & \\
\hline Satisfaction & -0.05 & 0.01 & -0.04 & 0.14 & 0.14 & -0.16 & 0.28 & 0.16 & 0.17 & -0.09 & 1.00 \\
\hline
\end{tabular}

3. Correlation matrix for T2 control group-for SEM Model 1

\begin{tabular}{|c|c|c|c|c|c|c|c|c|c|c|c|}
\hline & Age & Education & Married & $\begin{array}{c}\text { Wealth } \\
\text { index }\end{array}$ & Adhere1 & Adhere2 & Adhere3 & Adhere4 & Adhere5 & $\begin{array}{c}\text { Speed } \\
\text { of ART } \\
\text { initiation }\end{array}$ & Satisfaction \\
\hline Age & 1.00 & & & & & & & & & & \\
\hline Education & 0.04 & 1.00 & & & & & & & & & \\
\hline Married & 0.21 & 0.07 & 1.00 & & & & & & & & \\
\hline Wealth index & 0.03 & 0.27 & -0.04 & 1.00 & & & & & & & \\
\hline Adhere1 & 0.13 & 0.00 & -0.02 & 0.10 & 1.00 & & & & & & \\
\hline Adhere2 & -0.03 & -0.01 & 0.10 & -0.01 & 0.55 & 1.00 & & & & & \\
\hline Adhere3 & 0.29 & -0.27 & 0.20 & 0.19 & 0.50 & 0.64 & 1.00 & & & & \\
\hline Adhere 4 & 0.12 & 0.08 & 0.06 & 0.11 & 0.86 & 0.63 & 0.63 & 1.00 & & & \\
\hline Adhere 5 & 0.06 & -0.04 & -0.06 & 0.13 & 0.89 & 0.59 & 0.51 & 0.87 & 1.00 & & \\
\hline $\begin{array}{l}\text { Speed of ART } \\
\text { initiation }\end{array}$ & -0.05 & 0.03 & 0.18 & -0.08 & -0.06 & -0.12 & -0.16 & -0.08 & -0.09 & 1.00 & \\
\hline Satisfaction & -0.12 & 0.04 & -0.02 & 0.01 & 0.06 & 0.09 & 0.05 & 0.23 & 0.07 & -0.04 & 1.00 \\
\hline
\end{tabular}

4. Correlation matrix for T2 intervention group-for SEM Model 1

\begin{tabular}{|c|c|c|c|c|c|c|c|c|c|c|c|}
\hline & Age & Education & Married & $\begin{array}{l}\text { Wealth } \\
\text { index }\end{array}$ & Adhere1 & Adhere2 & Adhere3 & Adhere4 & Adhere 5 & $\begin{array}{c}\text { Speed } \\
\text { of ART } \\
\text { initiation }\end{array}$ & Satisfaction \\
\hline Age & 1.00 & & & & & & & & & & \\
\hline Education & -0.03 & 1.00 & & & & & & & & & \\
\hline Married & 0.10 & 0.00 & 1.00 & & & & & & & & \\
\hline Wealth index & 0.10 & 0.16 & -0.10 & 1.00 & & & & & & & \\
\hline Adhere1 & 0.03 & -0.08 & 0.16 & -0.06 & 1.00 & & & & & & \\
\hline Adhere2 & 0.08 & -0.06 & 0.04 & -0.13 & 0.46 & 1.00 & & & & & \\
\hline Adhere3 & 0.08 & -0.23 & 0.17 & -0.09 & 0.62 & 0.68 & 1.00 & & & & \\
\hline Adhere4 & -0.09 & -0.11 & 0.04 & -0.10 & 0.85 & 0.46 & 0.56 & 1.00 & & & \\
\hline Adhere5 & 0.02 & -0.15 & 0.02 & 0.00 & 0.95 & 0.42 & 0.63 & 0.87 & 1.00 & & \\
\hline $\begin{array}{l}\text { Speed of ART } \\
\text { initiation }\end{array}$ & -0.07 & 0.14 & -0.02 & 0.12 & -0.23 & -0.22 & -0.16 & -0.20 & -0.24 & 1.00 & \\
\hline Satisfaction & -0.09 & 0.01 & 0.00 & -0.04 & 0.15 & 0.11 & 0.21 & 0.27 & 0.18 & -0.08 & 1.00 \\
\hline
\end{tabular}


5. Correlation matrix for control and intervention groups at T1-for SEM Model 2

Wealth

Speed

of ART

Age Education Married index Adhere1 Adhere2 Adhere3 Adhere4 Adhere5 initiation SatisfactionIntervention

Age $\quad 1.00$

\begin{tabular}{lll}
\hline Education & 0.03 & 1.00
\end{tabular}

\begin{tabular}{llll}
\hline Married & 0.14 & 0.11 & 1.00
\end{tabular}

\begin{tabular}{llll}
\hline Wealth index 0.09 & 0.31 & 0.05 & 1.00
\end{tabular}

$\begin{array}{llllll}\text { Adhere1 } & -0.03 & -0.11 & 0.04 & -0.12 & 1.00\end{array}$

\begin{tabular}{lllllll}
\hline Adhere2 & -0.01 & -0.16 & -0.11 & -0.17 & 0.27 & 1.00
\end{tabular}

\begin{tabular}{llllllll}
\hline Adhere3 & -0.11 & -0.12 & -0.06 & -0.01 & 0.44 & 0.43 & 1.00
\end{tabular}

\begin{tabular}{lllllllll}
\hline Adhere4 & 0.06 & -0.13 & 0.13 & -0.18 & 0.77 & 0.16 & 0.33 & 1.00
\end{tabular}

\begin{tabular}{llllllllll}
\hline Adhere5 & 0.08 & -0.12 & 0.09 & -0.06 & 0.72 & 0.47 & 0.51 & 0.72 & 1.00
\end{tabular}

\begin{tabular}{lllllllllll}
\hline Speed of & -0.05 & 0.03 & 0.09 & 0.03 & -0.09 & -0.19 & -0.10 & 0.06 & -0.01 & 1.00
\end{tabular}

ART

initiation

\begin{tabular}{lllllllllll}
\hline Satisfaction -0.02 & -0.01 & -0.02 & 0.02 & 0.03 & 0.01 & 0.25 & 0.13 & 0.11 & -0.09 & 1.00
\end{tabular}

\begin{tabular}{lllllllllllll} 
Intervention & 0.17 & 0.18 & 0.14 & 0.23 & -0.07 & -0.08 & -0.06 & -0.07 & -0.19 & -0.09 & 0.10 & 1.00 \\
\hline
\end{tabular}

6. Correlation matrix for control and intervention groups at T2-for SEM Model 2

$\begin{array}{ll}\text { Speed } & \text { Spalth } \\ \text { of ART }\end{array}$

Age Education Married index Adhere1 Adhere2 Adhere3 Adhere4 Adhere5 initiation Satisfaction Intervention

Age $\quad 1.00$

\begin{tabular}{lll}
\hline Education & 0.01 & 1.00
\end{tabular}

\begin{tabular}{llll}
\hline Married & 0.15 & 0.04 & 1.00
\end{tabular}

\begin{tabular}{llll}
\hline Wealth index 0.07 & 0.25 & -0.06 & 1.00
\end{tabular}

\begin{tabular}{llllll}
\hline Adhere1 & 0.08 & -0.05 & 0.07 & 0.00 & 1.00
\end{tabular}

\begin{tabular}{lllllll}
\hline Adhere2 & 0.03 & -0.05 & 0.07 & -0.10 & 0.50 & 1.00
\end{tabular}

\begin{tabular}{llllllll}
\hline Adhere3 & 0.17 & -0.25 & 0.19 & 0.02 & 0.56 & 0.66 & 1.00
\end{tabular}

\begin{tabular}{lllllllll}
\hline Adhere4 & 0.01 & -0.02 & 0.05 & -0.02 & 0.85 & 0.54 & 0.59 & 1.00
\end{tabular}

\begin{tabular}{llllllllll}
\hline Adhere5 & 0.04 & -0.10 & -0.02 & 0.06 & 0.92 & 0.50 & 0.57 & 0.87 & 1.00
\end{tabular}

$\begin{array}{lllllllllll}\text { Speed of } & -0.06 & 0.05 & 0.08 & -0.03 & -0.14 & -0.16 & -0.15 & -0.13 & -0.16 & 1.00\end{array}$

ART

initiation

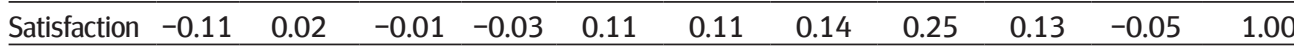

\begin{tabular}{lllllllllllll}
\hline Intervention & 0.03 & 0.17 & 0.03 & 0.34 & -0.05 & -0.09 & -0.03 & -0.06 & -0.01 & -0.14 & -0.05 & 1.00
\end{tabular}

\section{References}

1. WHO. Available at http://www.aho.afro.who.int/profiles information/ index.php/Ethiopia:Analytical_summary_-_HIV/AIDS. Accessibility verified June 20, 2017.

2. MOH Ethiopia. Country progress report on the HIV response, 2014. Addis Ababa: Federal Democratic Republic of Ethiopia; 2014.

3. WHO. Adherence to long-term therapies: policy for action. Geneva: WHO; 2001.

4. Bader A, Kremer H, Erlich-Trungenberger I, et al. An adherence typology: coping, quality of life, and physical symptoms of people living with HIV/ AIDS and their adherence to antiretroviral treatment. Med Sci Monit. 2006;12(12):CR493-CR500.

5. Luszczynska A, Sarkar Y, Knoll N. Received social support, self-efficacy, and finding benefits in disease as predictors of physical functioning and adherence to antiretroviral therapy. Patient Educ Couns. 2007;66(1):37-42.

6. Mannheimer S, Matts J, Telzak E, et al. Quality of life in HIV-infected individuals receiving antiretroviral therapy is related to adherence. AIDS Care. 2005;17(1):10-22.

7. Parsons T, Braaten A, Hall C, Robertson K. Better quality of life with neuropsychological improvement on Haart. Health Qual Life Outcome. 2006:4:11. doi:10.1186/1477-7525-4-11.
8. Ruiz-Pérez I, Olry dLLA, López-Ruz M, et al. Clinical status, adherence to HAART and quality of life in HIV-infected patients receiving antiretroviral treatment. Enferm Infecc Microbiol Clin. 2005;23(10):581-585.

9. UNAIDS. Fast-Track. Geneva; 2014

10. Stover J, Bollinger L, Izazola J, et al. What is required to end the AIDS epidemic as a public Health Threat by 2030? The cost and impact of the Fast-Track approach. PLoS One. 2016;11(5):e0154893. doi: 10.1371/journal.pone.0154893.

11. WHO. Media Center. HIV/AIDS. Available at http://www.who.int/mediacentre/factsheets/fs360/en/. Accessibility verified March 5, 2017.

12. Stange K. The problem of fragmentation and the need for integrative solutions. Ann Fam Med. 2009;7:100-103. doi: 10.1370/afm.971.

13. PEPFAR. Ethiopia country/regional operational plan (COP/ROP) 2016 strategic direction summary. Washington, DC: PEPFAR; 2016.

14. Berwick D. Launching accountable care organizations-the proposed rule for the Medicare shared savings program. N Engl J Med. 2011. doi:10.1056/nejmp1103602.

15. Thomas J, Reynolds H, Bevc C, Tsegaye A. Integration opportunities for HIV and family planning services in Addis Ababa, Ethiopia: an organizational network analysis. BMC Health Serv Res. 2014;14:22. doi: 10.1186/1472-6963-14-22.

16. Thomas J, Reynolds H, Alterescu X, Bevc C, Tsegaye A. Improving referrals and integrating family planning and HIV services through organizational network strengthening. Health Policy Plan. 2016;31(3):302-308. doi: 10.1093/heapol/cz058. 
17. Rosenheck R, Lam J, Morrissey J, et al. Service Systems integration and outcomes for mentally ill homeless persons in the ACCESS program. Psychiatr Serv. 2002; 53(8): 958-966.

18. Morrissey J, Calloway M, Thakur Nl, et al. Integration of service systems for homeless persons with serious mental illness through the ACCESS program. Psychiatr Serv. 2002; 53(8): 949-957.

19. Provan K, Milward H. Do networks really work? A framework for evaluating public-sector organizational networks. Public Admin Rev. 2001; 61(4): 414-423.

20. Morrissey J, Tausig M, Lindsey M. Community mental health delivery systems: a network perspective. Am Behav Scientist. 1985: 28(5): 704-720.

21. Provan K, Veazie M, Teufel-Shone N, Huddleston C. Network analysis as a tool for assessing and 13 building community capacity for provision of chronic disease services. Health Promot Pract. 2004; 5(2): 174-181. doi: $10.1177 / 1524839903259303$.

22. Thomas J, Isler $M$, Carter C, Torrone E. An interagency network perspective on HIV prevention. Sex Transm Dis. 2007; 34(2): 71-75. doi: 10.1097/01.olq.0000223281.30734.b1.

23. McKinney M, Morrissey J, Kaluzny A. Interorganizational exchanges as performance markers in a community cancer network. Health Serv Res. 1993; 28(4): 459-478

24. Abaynew Y, Deribew A, Deribe K. Factors associated with late presentation to HIV/AIDS care in South Wollo Zone Ethiopia: a case-control study. Biomed Central. 2011; 8(8):1-6. doi: 10.1186/1742-6405-8-8.

25. WHO. Guideline on when to start antiretroviral therapy and on pre-exposure prophylaxis for HIV. Geneva: WHO; 2015.

26. $\mathrm{MOH}$ Ethiopia. Guidelines for management of opportunistic infections and antiretroviral treatments in adolescents and adults in Ethiopia. Addis Ababa; 2008.

27. AIDS.gov. CD4 count. Available at http://www.aids.gov/hiv-aidsbasics/ just-diagnosed-with-hiv-aids/understand-your-test-results/cd4-count/. Accessibility verified November 18, 2014

28. Bollen K Structural equations with latent variables. New York. Wiley; 1989.

29. Bialosiewicz S, Murphy K, Berry T. Do our measures measure up? The critical role of measurement invariance. Paper presented at: An Introduction to Measurement Invariance Testing: Resource Packet for Participants; October 2013; Washington DC. USA. Available at http://comm.eval.org/ HigherLogic/System/DownloadDocumentFile.ashx?DocumentFileKey= 63758fed-a490-43f2-8862-2de0217a08b8. Accessibility verified December 27, 2017.

30. Sousa KH, West SG, Moser SE, Harris JA, Cook SW. Establishing measurement invariance: English and Spanish Paediatric Asthma Quality of Life Questionnaire. Nurs Res.2012; 61(3): 171-180.

31. Aiken L, Stein J, Bentler P. Structural equation analyses of clinical subpopulation differences and comparative treatment outcomes: characterizing the daily lives of drug addicts. Am Psychol Assoc. 1994; 62(3): 488-499.

32. Hancock $G$. Structural equation modeling of hypothesis testing of latent variable means. Measure Evaluat Counsel Dev. 1997; 30: 91-105.

33. Dimitrov DM. Comparing groups on latent variables: a structural equation modeling approach. Work. 2006; 26(4): 429-436.

34. Muthén L, Muthén B. Mplus User's Guide. 7th ed. Los Angeles, CA: Muthén \& Muthén; 1998-2011.

35. Brown T. Confirmatory factor analysis for applied research. New York: Guilford Press; 2006

36. Hu L, Bentler P. Evaluating model fit. In: Hoyle RH, ed. Structural equation modeling. London: Sage; 1995.

37. Gari S, Doig-Acuña C, Smail T, Malungo JR, Martin-Hilber A, Merten S. Access to HIV/AIDS care: a systematic review of socio-cultural determinants in low and high income countries. BMC Health Serv Res. 2013; 13: 198. doi: 10.1186/1472-6963-13-198.

38. Cohen MS, Chen YQ McCauley M et al Prevention of HIV-1 infection with early antiretroviral therapy. N Engl J Med. 2011; 365(6): 493-505.

39. WHO. Adherence to long-term therapies: evidence for action. Geneva: World Health Organization; 2003.

40. Roberts K. Physician-patient relationships, patient satisfaction, and antiretroviral medication adherence among HIV-infected adults attending a public health clinic. AIDS Patient Care STDs. 2002; 16(1): 43-50.

41. Chimbindi N, Bärnighausen T, Newell M. Patient satisfaction with HIV and TB treatment in a public programme in rural KwaZulu-Natal: evidence from patient-exit interviews. BMC Health Serv Res. 2014: 14: 32. doi: 10.1186/1472-6963-14-32.

42. Dang B, Westbrook R, Black W, Barradas R, Giordano T. Examining the link between patient 14 satisfaction and adherence to HIV care: a structural equation model. PLoS One. 2013; 8(1): e54729. 